\title{
La función percibida en el diseño de automóviles "populares" y su importancia para el mercado
}

\section{The perceived function in the design of "popular" cars and their importance for the Market}

\section{A função percebida no desenho de carros "populares" e sua importância para o mercado}

\author{
André Demaison ${ }^{1, *}$, Galdenoro Botura Jr ${ }^{1}$, Luis Carlos Paschoarelli ${ }^{1}$ \\ 1- Universidade Estadual Paulista - Campus Bauru - Av. Eng. Luiz E. C. Coube, 14-01 17033-360 - Bauru, São Paulo - Brasil \\ *E-mail: demaison@gmail.com
}

Recibido: 21/10/2020; Aprobado 09/04/2021

\section{Resumen}

Los consumidores de automóviles de menor valor a menudo buscan versiones que parezcan "premium" para satisfacer sus vanidades. Para escapar del estigma asociado a los automóviles más baratos y sencillos para la venta, los fabricantes trabajan en la estética de estos vehículos para impactar positivamente en la autoestima de los propietarios. Este artículo analiza los valores estéticos de los automóviles, presentando el concepto de "automóvil popular" y la evolución histórica de este mercado. Se elaboró un cuestionario de Diferencial Semántico con los modelos de "entrada" más vendidos en Brasil en 2019, además de clásicos "populares" de décadas pasadas. Se presenta y discute la función percibida de lo "popular" en el mercado nacional a partir del análisis estadístico de los resultados obtenidos de las consultas con los consumidores. Se identificó que una estética más elaborada, que se refiere al aspecto de vehículos más costosos, la que genera mayor atractivo para los usuarios.

Palabras clave: Diseño; estética; automóviles; función percibida; automóviles populares.

\section{Abstract}

Consumers of lower-value automobiles often look for versions that look "premium" to satisfy their vanities. To escape the stigma attached to "popular" cars - the cheapest and simplest for sale by automakers -, manufacturers work on the aesthetics of these vehicles to positively impact the owners' self-esteem. This article discusses the aesthetic values of automobiles, presenting the concept of "popular car" and the historical evolution of this market. A Semantic Differential questionnaire was prepared with the best-selling "entry" models in Brazil in 2019, in addition to "popular" classics from past decades. The perceived function of the "popular" in the national market is presented and discussed based on the statistical analysis of the results obtained from consultations with consumers. It was identified that a more elaborate aesthetic, which refers to the look of more expensive vehicles, generates greater attraction for users.

Keywords: Design; aesthetics; automobiles; perceived function; popular cars.

\section{Resumo}

Consumidores de automóveis de menor valor buscam, muitas vezes, versões com aparência considerada "premium" para satisfazerem suas vaidades. Para fugir do estigma vinculado aos carros "populares" - os mais baratos e simples à venda pelas montadoras -, os fabricantes trabalham a estética desses veículos para impactar positivamente a autoestima dos proprietários. Este artigo discute acerca dos valores estéticos dos automóveis, apresentando o conceito de carro "popular" e a evolução histórica desse mercado. Foi elaborado um questionário de Diferencial Semântico com os modelos "de entrada" mais vendidos no Brasil em 2019, além de clássicos "populares" de décadas passadas. A função percebida dos "populares" no mercado nacional é apresentada 
e discutida com base na análise estatística dos resultados obtidos a partir de consultas realizadas junto aos consumidores. Identificou-se que uma estética mais elaborada, que remete ao visual de veículos mais caros, gera maior atração nos usuários.

Palavras-chave: Design; estética; automóveis; função percebida; carros populares.

\section{Introdução}

A estética de um produto é, possivelmente, o primeiro fator de impacto para um usuário. Por meio dos olhos é que se identificam as características de uso e decide adquirir, utilizar ou ao menos entender a funcionalidade dos objetos. [1] define a função estética dos produtos como "um aspecto psicológico da percepção sensorial durante o seu uso". Estéticas bem resolvidas permitem a identificação direta das funções práticas de um objeto, fazendo com que o usuário sinta-se mais confiante ao optar por um produto.

Com relação aos automóveis, a estética permite ao sujeito identificar o uso de cada veículo de modo claro. Carros off-roads, familiares ou utilitários de carga são constantemente identificáveis por meio das aparências, informando suas funções e principais características. Isso ajuda o usuário a adquirir o produto que, sob sua ótica, mais se adeque às suas necessidades. A estética permite, ainda, que o usuário adquira um automóvel que tenha identificação com sua personalidade, mesmo que isso signifique não seguir a função prática para qual ele foi projetado.

Para [1], "pode-se deduzir que a configuração de produtos industriais significa dotar os produtos de funções estéticas, atendendo à percepção multissensorial do usuário". Assim, observa-se que a utilização de elementos que procuram emular funções, não compatíveis com as reais características de uma versão do automóvel, confunde o usuário leigo, induzindo-o a possíveis utilizações inadequadas, como no caso de versões esportivas que não apresentem melhorias técnicas que se traduzam em aumento de performance.

Este estudo apresenta, por meio da visão de usuários, o impacto da estética no tocante à percepção da faixa de preço dos veículos "de entrada" atuais, utilizando como parâmetro a comparação com carros considerados atualmente clássicos, mas que foram os mais baratos das montadoras em seus lançamentos.

\section{O automóvel e seu impacto sociocultural}

O Brasil adotou majoritariamente o modal rodoviário ainda nas décadas de 1950 e 1960 e, desde então, vários programas foram desenvolvidos para que a "família média brasileira" pudesse adquirir seu próprio carro, sendo o consumo de automóveis incentivado por meio de diversas medidas político-econômicas [2, 3].

Ações voltadas para o consumo de automóveis foram idealizadas para facilitar a compra de modelos classificados como "populares", os mais baratos de um fabricante. O programa adotado pelo Governo Federal de redução de impostos para veículos abaixo de 1000 cilindradas [4], nos anos 1990, gerou uma "explosão" no mercado de carros "populares". O impacto cultural causado, desde o surgimento do automóvel, mostra a importância social do produto, como o fator simbólico do sujeito ser "dono de carro" [5]. O automóvel passou a ser visto, no mundo moderno, como um produto que traz "economia de tempo, utilidade, trabalho, liberdade, independência e prestígio" [5]. Ter um carro significa fazer parte de um grupo visto como "melhor sucedido", pois ter um veículo particular traz independência em relação ao transporte público. Assim, "à medida que a renda familiar cresce, também cresce a mobilidade pessoal; pessoas de maior poder aquisitivo costumam usar mais o automóvel do que qualquer outro meio de transporte" [2].

Um estudo de caso da cidade de São Paulo (SP) mostra ainda que pedestres, ciclistas e mesmo usuários de transportes públicos são tratados, socialmente, como "menores" pelo poder público e pelos donos de automóveis que recebem as principais obras ou demais melhorias para a mobilidade urbana [2].

Porém, o fato de ganhar o status de "dono de automóvel" pode ser minimizado pela versão do carro comprado. Adquirir um modelo simples, antiquado, usado ou fora de moda pode causar ao usuário o efeito social contrário, sinalizando que o sujeito não está "em boas condições de comprar algo melhor". Nesse ponto, a estética do carro é um diferencial na percepção dos usuários. É possível afirmar que automóveis atuais e esteticamente atraentes, mesmo os de menor custo, mas que não aparentam ser "populares", trazem o efeito social desejado. [6] afirma que as pessoas querem veículos bonitos que "seus vizinhos possam admirar".

A cultura implantada de ser dono de automóvel é forte entre os consumidores, sendo o carro um objeto de desejo $[3,7]$. Adquirir um veículo para a mobilidade parece estar restrito apenas para consumidores de renda mais baixa, para quem precisa do carro para trabalho, ou para quem não se incomoda com marcas, modelos ou versões dos carros. Porém, mesmo para esses usuários, alguns recursos existentes acabam sendo necessários: compram o modelo básico, mas possivelmente com ar-condicionado ou direção hidráulica. Já para os consumidores mais entusiastas, torna-se imperativo ser proprietário de um modelo atual ou que esteja em voga.

Considerando as questões sociais, o consumidor procura adquirir um carro que o permite ser visto por seus pares como bem-sucedido ou alguém de bom gosto nas suas escolhas. Mesmo que seja o modelo básico, ter o carro da moda desperta desejos. Assim, é comum que 
fabricantes e montadoras façam grandes investimentos no design dos automóveis, buscando atingir o emocional dos usuários. Um exemplo é o caso do Jeep Renegade, no qual se encontram referências aos veículos Jeep clássicos dos anos 1950 em elementos como as lanternas, faróis, grade e até pequenos desenhos nos para-brisas [8]. Assim, "produtos com design inovador, lúdico ou até mesmo retrô, associados a um possante posicionamento de marca, são capazes de gerar uma espécie de paixão no comprador em potencial [9]".

\section{Simples, porém bonito: a estética do carro popular}

A história do "carro popular" no mundo remete ao Ford $\mathrm{T}$ [10]. Trata-se da primeira tentativa de um fabricante em criar um produto acessível ao grande público, fórmula que foi repetida em diversas outras ocasiões (VW Fusca, Morris Mini, Fiat 500, Citroën 2CV) durante as décadas de 1940 e 1950. Um dos mais conhecidos carros "populares" de todos os tempos, o Fusca (originalmente Volkswagen, ou "carro do povo"), possuía linhas bastante simples e arredondadas. O carro tornou-se um clássico com o passar do tempo, tendo ficado 65 anos em produção mundial - entre 1938 (lançamento na Alemanha) e 2003 (fim da produção no México). Foi produzido no Brasil entre 1959 e 1986, tendo retornado ao mercado brevemente entre 1993 e 1996. Este novo produto introduzido no mercado, segundo o manual de Oslo [11] e, também, por [12] e [13], causou um grande impacto, agregando valor à marca e rendendo dividendos aos fabricantes. Ainda hoje, é um dos carros mais vendidos de todos os tempos [14].

As iniciativas de se aproveitar de um nicho de mercado com a venda de carros mais baratos no Brasil aconteceram já nos anos 1960 [15], com veículos como o Willys Dauphine "Teimoso" (Figura 01), o Fusca "Pé-de-Boi", o Simca Profissional, DKW Pracinha/Caiçara e o potente esportivo "simplificado" Dodge Dart SE. Era comum a remoção de elementos estéticos e equipamentos, como frisos, adesivos, cromados, carpetes, cinzeiro, revestimentos e, às vezes, até mesmo retrovisores [4]. Fundamentalmente, eram os mesmos carros de linha, porém "depenados" pelas montadoras para baratear os preços. Dessa maneira, o consumidor tinha a opção de ter o carro desejado sem pagar muito mais por isso. As alterações estéticas deixavam os veículos com uma aparência muito simples, mas mantinham as linhas básicas padrão. Um Dodge Dart SE continuava sendo um Dodge Dart - e essa era, provavelmente, a visão que os vizinhos teriam do dono do automóvel.

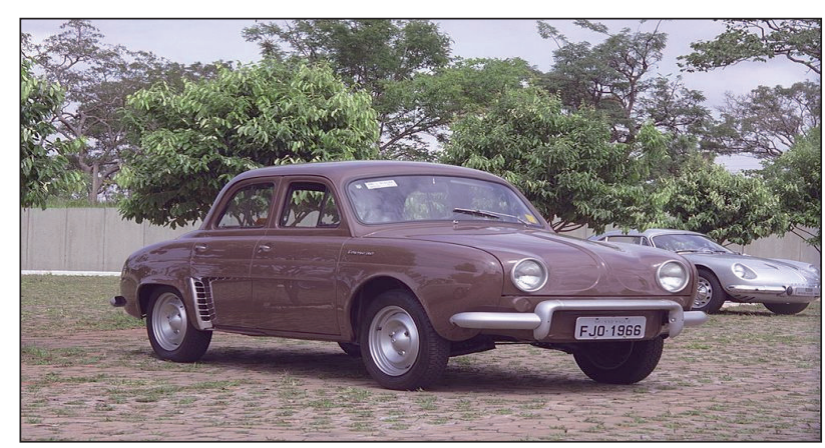

Figura 1: Willys Dauphine "Teimoso", provavelmente um dos primeiros "populares" do Brasil

Fonte: https://commons.wikimedia.org/wiki/File:Renault_Teimoso.jpg/ Acesso em 08 jan 2020.

Apesar das montadoras terem investido em versões mais baratas de seus carros ao longo das décadas, o Fiat Uno Mille (Figura 2) - versão do Uno lançada em 1990 - foi o precursor do conceito de carro popular da maneira como se entende hoje, carros originados a partir dos incentivos fiscais $[10,15,16]$, com a redução de impostos para os fabricantes $[4,10,17]$ - portanto, diferente do conceito do Willys Dauphine "Teimoso" e outros citados.

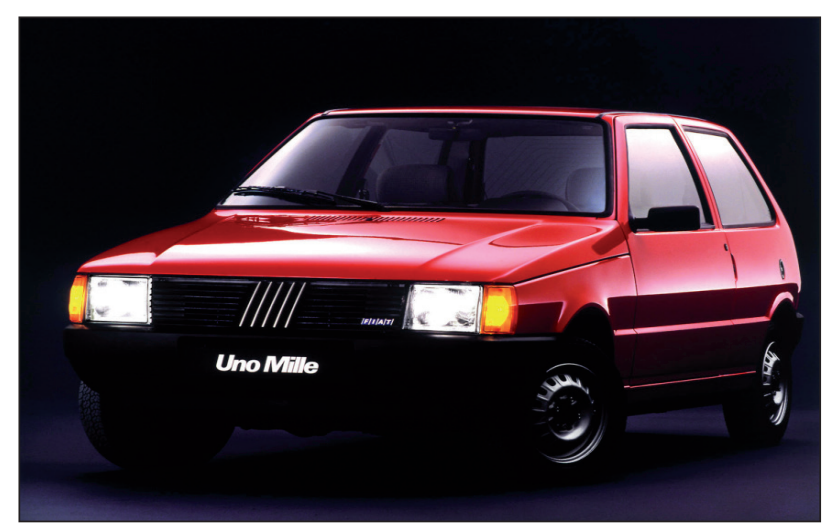

Figura 2: Fiat Uno Mille, versão despojada de equipamentos da linha. Fonte: http://motor1.uol.com.br/news/117608/carros-para-sempreuno-mille-a-historia-do-precursor-dos-populares/ Acesso em 12 jan 2020.

A história do Uno possui similaridade com a do Fusca. Lançado no mercado brasileiro em 1984 para ser o carro mais barato da Fiat, também chamou atenção por suas linhas simples. Porém, diferentemente do Fusca, era um desenho quadrado - uma estética considerada bastante moderna para a época. Com o sucesso do carro, a Fiat lançou a versão Mille: além de ter sido "oficialmente" o primeiro carro popular $[10,15,16]$, dentro do conceito dos que se aproveitaram do programa de incentivo do IPI baixo para motores abaixo de 1000 cilindradas, o Uno Mille também pode ser considerado o último carro "popular puro" do Brasil [10]. Por se tornar referência entre os "populares", a Fiat chegou a tirar de linha todas as outras versões do carro, mantendo entre 1996 e 2014 apenas o Mille (sem o nome Uno) à venda.

Os carros "populares" eram bastante espartanos tanto 
esteticamente quanto no tocante a equipamentos. Basicamente, aliou-se o uso do motor 1000 cilindradas (1.0) à simplificação do modelo, porém sem os excessos de épocas anteriores que pudessem comprometer a segurança ou minimamente o conforto, como a remoção de lanternas ou a existência de bancos sem revestimento. Vários equipamentos passaram a ser disponibilizados como itens opcionais, como o retrovisor do lado direito, adornos estéticos, rádio, relógio e afins. Com interior modesto e poucos mostradores no painel, os “populares" eram vendidos em torno dos US\$ 7.500 em 1994, ano no qual o câmbio da moeda girava em torno de R\$ 1,00. Em valores de final de 2019, próximos dos R\$30.000,00, considerando o dólar da época em torno dos R\$ 4,00. Para fins de comparação, a versão mais completa dos mesmos carros poderia chegar próximo dos US\$ 12.500 (R\$ 50.000 em 2019).

Criou-se naquela década, assim, um efervescente mercado dos chamados "carros 1000": Além do Uno Mille, havia o VW Gol 1000 (Figura 03), o Ford Escort Hobby e o GM Chevette Junior, para citar os pioneiros [10]. Todas as grandes fabricantes do mercado nacional lançaram suas versões simplificadas com motores 1000 cilindradas para competir nesta nova faixa de mercado. Posteriormente, outras fabricantes que se instalaram no Brasil seguiram este mesmo modelo, como o Renault Clio e o Peugeot 106.

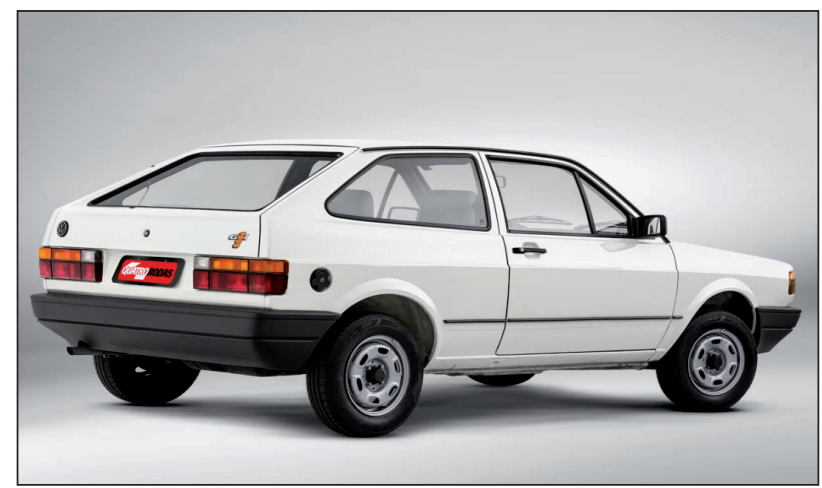

Figura 3: Volkswagen Gol 1000, versão "popular" da linha. Fonte: https://quatrorodas.abril.com.br/noticias/classicos-o-popularvw-gol-1000/ Acesso em 04 jan 2020.

Aos poucos, com o sucesso do "carro 1000", a estratégia das fabricantes mudou da simplificação de um modelo já existente para o desenvolvimento de um produto próprio para os veículos "de entrada", passando a projetar carros especificamente para o segmento. Atualmente os modelos possuem desde versões mais básicas ("populares") até as mais equipadas, chamadas "compactos premium". Mesmo nas versões mais simples, esses veículos são modelos esteticamente mais apurados, de forma a não parecerem "populares”. Segundo [1], "a condição para a formação do conceito de valor é a aparência estética dos produtos". Tal recurso faz com que o estigma de "popular" - termo constantemente relacionado a produtos baratos e/ou de qualidade duvidosa - diminua, trazendo mais autoestima ao proprietário de carros em faixas de preço mais acessíveis.

O desenho atual dos automóveis propicia identificar nos chamados "populares" uma mudança de paradigma do ponto de vista estético. Saem as linhas simples, sejam quadradas ou arredondadas, e aparecem desenhos mais rebuscados, com vincos, entalhes e demais artifícios para que o modelo não aparente simplicidade extrema. Tornase imperativo que o carro seja "bonito". Produtos como o Renault Logan e o Toyota Etios, modelos "de entrada" que prezam pela simplicidade de formas, sofreram no Brasil na época dos lançamentos com o estigma de serem carros "feios" devido às suas linhas quadradas. Tal fato ficou tão evidente que a própria Renault, na ocasião do lançamento da segunda geração do Logan, veiculou uma propaganda que fazia chacota com o fato da versão anterior ser feia e a atual ter ficado bonita ${ }^{1}$.

Essa mudança na estética dos carros “populares” dá-se, fundamentalmente, pela preferência dos próprios consumidores. Conforme [3], "no Brasil, terra do carro popular de motor $1000 \mathrm{cc}$, o fabricante tem dificuldade de vender um carro simples que não apresente um estilo atraente". Nas décadas de 1960 e 1970, as fabricantes procuravam manter a estética padrão dos automóveis, apenas removendo adornos, já que a produção de um novo modelo era bastante cara. Atualmente, são desenvolvidos projetos "do zero", buscando atender o desejo do consumidor por produtos com aparência mais sofisticada.

Tal exigência também é vista em [10], para quem “os populares, no Brasil, nem de longe têm o mesmo apelo que tinham há três décadas". Para ele, os tais "populares" são básicos até demais, sendo que o consumidor prefere um produto mais refinado. [3] ainda afirma que, entre as fabricantes, "o maior desafio é conciliar preço e estilo, fazendo um automóvel bonito e baratinho".

\section{Materiais e Métodos}

Para medir a percepção do usuário quanto à função do produto a partir da sua estética, foi preparado e aplicado um questionário de Diferencial Semântico com 24 automóveis de diversas categorias ("populares," "familiares", "off-roads", "clássicos" e "esportivos"), selecionados a partir de consultas em revistas e fóruns automotivos especializados $^{2}$, livros $[3,5,7]$ e pré-testes, com o objetivo de elencar o(s) mais representativo(s) em cada quesito. $\mathrm{O}$ teste foi disponibilizado por meio de formulário on-line, no período entre 2 e 5 de outubro de 2019. Os participantes responderam voluntariamente acessando o link, sendo necessário ler e aceitar o TCLE (termo de consentimento livre e esclarecido), informar e-mail de contato e, então, declarar o nível de entusiasmo por automóveis entre 1 (nada entusiasta) e 5 (muito entusiasta).

1- Disponível em https://www.youtube.com/ watch?v=uSXbl6Tylv8. Acesso em 04 jan 2020 2- 4x4brasil.com.br, FlatOut!, Motor1, revista Quatro Rodas. 
O questionário contava com cinco perguntas e uma escala de avaliação para cada um dos automóveis, apresentados de maneira randomizada. Foram selecionados, para a categoria analisada, os quatro modelos "populares" mais vendidos no mercado nacional durante o primeiro semestre do ano de 2019, segundo a FENABRAVE ${ }^{3}$ (GM Onix, Ford Ka, Renault Kwid e Hyundai HB20) (Figura 4).
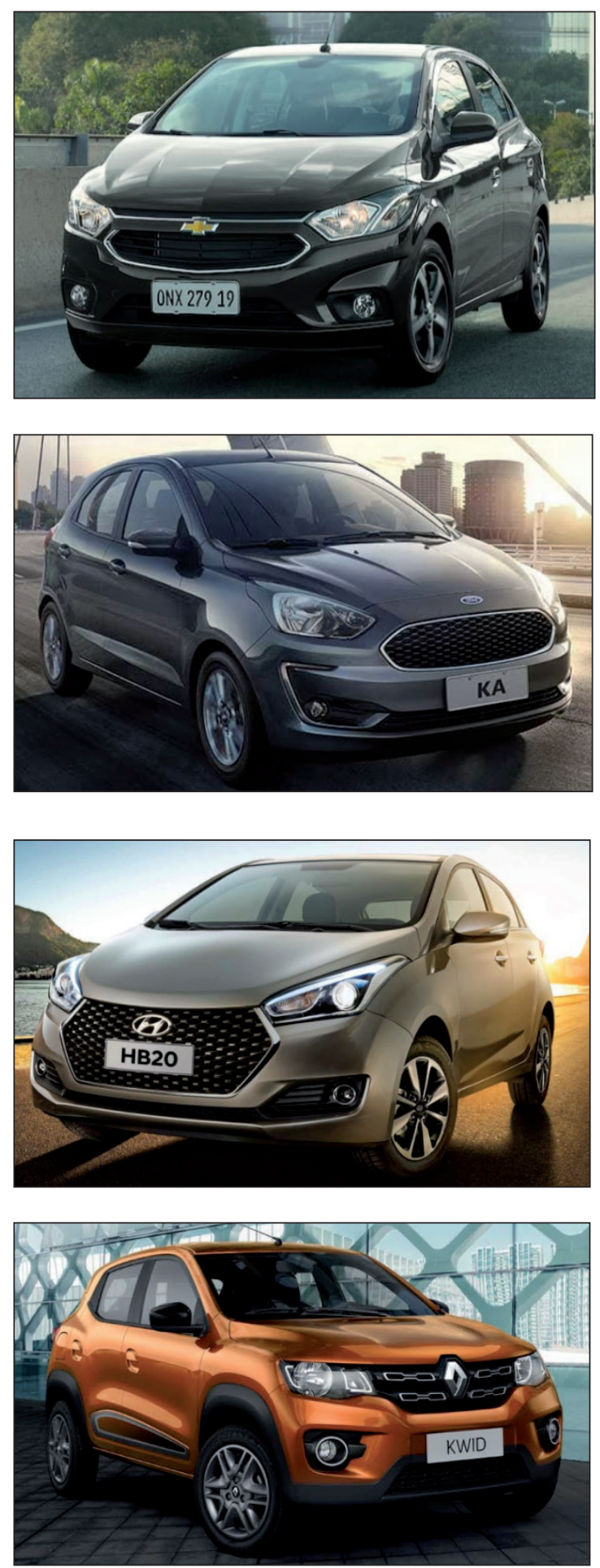

Figura 4: GM Onix, Ford Ka, Hyundai HB20 e Renault Kwid selecionados para o estudo.

Fonte: Site das montadoras Chevrolet, Ford, Hyundai e Renault (2019).

3- Federação Nacional da Distribuição de Veículos Automotores.
Para fins de comparação, foram utilizados dois carros apresentados no questionário como clássicos, porém vendidos como "populares" em outras épocas: o VW Fusca (Figura 5) na versão mais atual vendida no Brasil (apelidada de "Itamar"), e o Fiat Uno CS (Figura 6), a versão mais completa no lançamento.

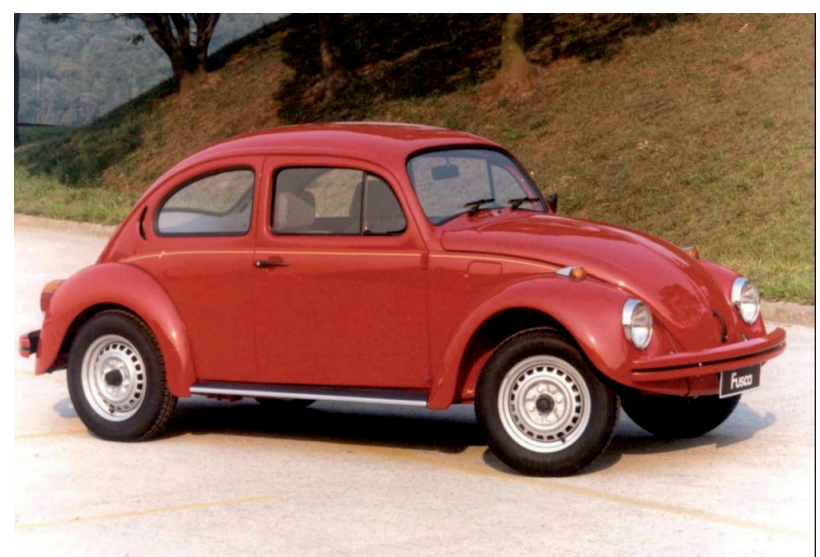

Figura 5: Volkswagen Fusca versão "Itamar", o último modelo vendido no Brasil

Fonte: http://motor1.uol.com.br/news/119677/carros-para-semprefusca-itamar-marcou-a-volta-dos-populares/ Acesso em 12 jan 2020.

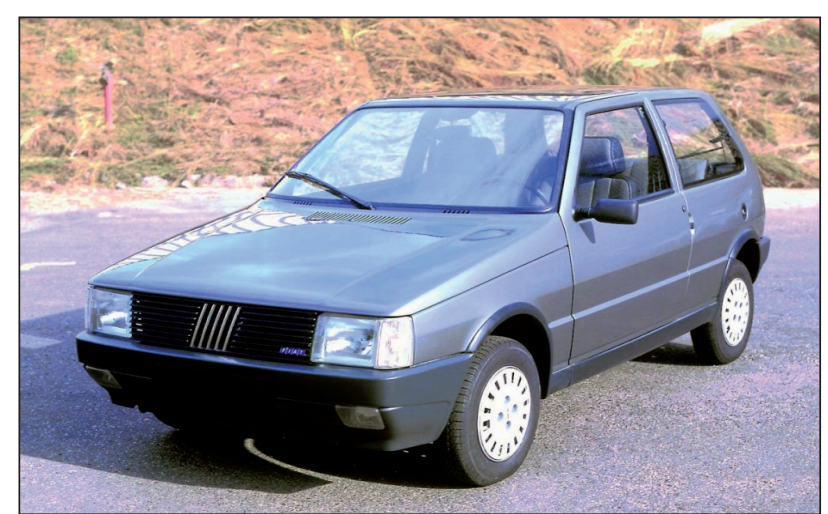

Figura 6: Fiat Uno CS

Fonte: http://revistaautoesporte.globo.com/Revista/Autoesporte/ foto/0,,63176924,00.jpg Acesso em 12 jan 2020.

A avaliação contou apenas com as imagens dos carros - obtidas de sites, propagandas oficiais das montadoras ou de veículos de comunicação -, incluindo os nomes dos automóveis e das montadoras, motorização da versão, potência do motor, quantidade de lugares e capacidade do porta-malas. Não foram especificados o ano ou o preço de cada carro, nem em qual categoria estava sendo analisado, esperando-se que os respondentes pudessem identificar a categoria "popular" (e outras) a partir da percepção pessoal. A opção pelas versões "top de linha" se deu por estarem, em teoria, mais completos em termos estéticos. Com isso evitou-se que o uso de imagens com os modelos completamente espartanos influenciasse no teste, fazendo com que, imediatamente, o respondente identificasse o modelo "popular" devido à estética desprovida de detalhes.

O formulário apresentava questões relevantes também às outras categorias analisadas na pesquisa, que deveriam 
ser respondidas. A pergunta que identificava a classificação dos "populares" era sobre o preço de compra do produto. Para isso, o respondente deveria marcar na escala de avaliação com cinco pontos em que ponto o veículo estava, na sua percepção, entre "não popular" (1) e "popular" (5). Ao responder sobre um modelo, o questionário passava para o próximo carro e não permitia retorno, evitando, assim, possíveis mudanças nas respostas.

\section{Resultados}

O estudo contou com respostas de 109 participantes. O nível médio de entusiasmo autodeclarado foi 2,86 (d.p. 1,27; Md 3). As respostas foram tabuladas e processadas para obtenção das medianas, médias e desvios padrão de cada modelo em cada categoria avaliada:

- GM Onix (média = 2,94, d.p. 1,17, Md 3)

- Renault Kwid (média = 3,64, d.p. 1,31, Md 4)

- Ford Ka (média = 3,84, d.p. 1,27, Md 4)

- Hyundai HB20 (média = 3,41, d.p. 1,20, Md 4)

- VW Fusca (média = 4,27, d.p. 1,04, Md 5)

- Fiat Uno (média = 4,67, d.p. 0,83, Md 5)

A análise estatística foi aplicada a partir da verificação da normalidade das amostras por meio do teste de Shapiro-Wilk, cujo resultado apontou a não normalidade $(\mathrm{p} \leq 0,05)$. Tal teste mostra se a distribuição da população que respondeu o teste é homogênea (normal, caso atinja o valor maior que o nível de significância $\mathrm{p}>0,05$ ) ou heterogênea (não normal, caso $\mathrm{p} \leq 0,05$ ). Levando em conta a não normalidade (distribuição heterogênea da população respondente, ou $\mathrm{p} \leq 0,05$ ), foi utilizado o teste de inferência não paramétrico de Friedman 2-way ANOVA. Esse teste faz a comparação entre pares, um a um, para checar se a diferença dos valores médios atingidos pelas amostras é estatisticamente significativa. Procurou-se, assim, validar os resultados obtidos que indicam diferenças entre os carros analisados do ponto de vista do respondente.

Valores estatisticamente distintos mostram que há, claramente, uma visão diferente sobre cada carro. Os resultados apontaram inexistência de diferença significativa dentre os pares de carros Kwid e Ka; Onix e HB20; Ka e Fusca; HB20 e Kwid (tabela 1). Isto denota que essas amostras, do ponto de vista estatístico, são similares para os respondentes.

Os valores de mediana apontaram similaridade entre as amostras Fusca e Uno (Md 5) e entre HB20, Ka e Kwid (Md 4), tendo o Onix atingido mediana 3. Tais dados mostram que o Fusca e o Uno aparentam ser os mais populares, seguidos pelos automóveis Kwid, Ka e HB20. Para eles, o Onix ficou em uma posição intermediária entre "não popular" e "popular".
Tabela 1: Comparação dos pares por teste de inferência Friedman 2-way ANOVA.

\begin{tabular}{|c|c|c|c|c|c|}
\hline \multicolumn{6}{|c|}{ Resultado geral - 109 respondentes } \\
\hline & Ford Ka & $\begin{array}{c}\text { Hyundai } \\
\text { HB2O }\end{array}$ & $\begin{array}{l}\text { Renault } \\
\text { Kwid }\end{array}$ & VW Fusca & Fiat Uno \\
\hline \multirow[t]{2}{*}{ GM Onix } & 0,00 & 0,72 & 0,00 & 0,00 & 0,00 \\
\hline & Ford Ka & 0,02 & 1,00 & 0,53 & 0,00 \\
\hline \multicolumn{2}{|c|}{ Legenda: } & $\begin{array}{c}\text { Hyundai } \\
\text { HB2O }\end{array}$ & 0,51 & 0,00 & 0,00 \\
\hline \multicolumn{3}{|c|}{ Há diferença estatística $(p \leq 0,05)$} & $\begin{array}{l}\text { Renault } \\
\text { Kwid }\end{array}$ & 0,03 & 0,00 \\
\hline \multicolumn{4}{|c|}{ Não há diferença estatística $(p>0,05)$} & VW Fusca & 0,04 \\
\hline
\end{tabular}

Foram analisados, ainda, os dados por nível de entusiasmo autodeclarado dos respondentes. Para tal, considerouse os níveis 1 e 2 como não-entusiastas, o nível 3 como parcialmente entusiastas e os níveis 4 e 5 como entusiastas. Entre os não-entusiastas (níveis 1 e 2), foram obtidos os seguintes dados:

- Onix (média = 2,84, d.p. 1,23, Md 3)

- Kwid (média = 3,23, d.p. 1,36, Md 3)

- $\mathrm{Ka}$ (média = 3,70, d.p. 1,30, Md 4)

- HB20 (média = 3,12, d.p. 1,29, Md 3)

- Fusca (média = 4,21, d.p. 1,10, Md 5)

- Uno (média = 4,58, d.p. 0,98, Md 5)

No nível 3, dos parcialmente entusiastas, os dados foram os seguintes:

- Onix (média = 2,84, d.p. 1,27, Md 3)

- Kwid (média = 3,61, d.p. 1,43, Md 4)

- $\mathrm{Ka}$ (média = 3,68, d.p. 1,49, Md 4)

- HB20 (média = 3,23, d.p. 1,28, Md 4)

- Fusca (média =4,39, d.p. 0,95, Md 5)

- Uno (média = 4,81, d.p. 0,60, Md 5)

Entre os mais entusiastas, autodeclarados nos níveis 4 e 5, foram encontrados os dados a seguir:

- Onix (média = 3,17, d.p. 0,98, Md 3)

- Kwid (média = 4,17, d.p. 0,92, Md 4)

- $\mathrm{Ka}$ (média = 4,17, d.p. 0,92, Md 4)

- HB20 (média = 3,94, d.p. 0,80, Md 4)

- Fusca (média =4,23, d.p. 1,06, Md 5)

- Uno (média = 4,66, d.p. 0,80, Md 5)

A normalidade dos dados foi também verificada por meio do teste de Shapiro-Wilk, para cada um dos três grupos, considerando como significância $\mathrm{p} \leq 0,05$. A partir da identificação da não normalidade, foram executados testes de inferência não paramétricos de Friedman 2-way ANO$V A$, para comparação dos pares em cada grupo. Identificouse a inexistência de diferença estatística significativa ( $\mathrm{p}$ $>0,05$ ) entre Onix e Ka, entre HB20 e Ka, entre Onix e HB20, entre Onix e Kwid, entre HB20 e Kwid, entre Ka e Kwid, entre Ka e Fusca e entre Uno e Fusca (tabela 2), para o grupo dos não entusiastas. 
Tabela 2: Comparação dos pares por teste de inferência Friedman 2-way ANOVA.

\begin{tabular}{|c|c|c|c|c|c|}
\hline \multicolumn{6}{|c|}{ Resultado - Não entusiastas (níveis 1 e 2) } \\
\hline & Ford Ka & $\begin{array}{c}\text { Hyundai } \\
\text { HB20 }\end{array}$ & $\begin{array}{c}\text { Renault } \\
\text { Kwid }\end{array}$ & VW Fusca & Fiat Uno \\
\hline GM Onix & 0,13 & 1,00 & 1,00 & 0,00 & 0,00 \\
\hline & Ford Ka & 0,65 & 1,00 & 1,00 & 0,01 \\
\hline \multicolumn{2}{|c|}{ Legenda: } & $\begin{array}{c}\text { Hyundai } \\
\text { HB20 }\end{array}$ & 1,00 & 0,00 & 0,00 \\
\hline \multicolumn{3}{|c|}{ Há diferença estatística $(p \leq 0,05)$} & $\begin{array}{c}\text { Renault } \\
\text { Kwid }\end{array}$ & 0,04 & 0,00 \\
\hline \multicolumn{4}{|c|}{ Não há diferença estatística $(p>0,05)$} & VW Fusca & 1,00 \\
\hline
\end{tabular}

Para os parcialmente entusiastas, o teste apontou diferença não significativa entre os mesmos pares, acrescentando Fusca e Kwid (tabela 3).

Tabela 3: Comparação dos pares por teste de inferência Friedman 2-way ANOVA.

\begin{tabular}{|c|c|c|c|c|c|}
\hline \multicolumn{6}{|c|}{ Resultado - Parcialmente entusiastas (nível 3) } \\
\hline & Ford Ka & $\begin{array}{c}\text { Hyundai } \\
\text { HB20 }\end{array}$ & $\begin{array}{c}\text { Renault } \\
\text { Kwid }\end{array}$ & VW Fusca & Fiat Uno \\
\hline GM Onix & 0,09 & 1,00 & 0,19 & 0,00 & 0,00 \\
\hline & Ford Ka & 0,73 & 1,00 & 1,00 & 0,02 \\
\hline \multicolumn{2}{|c|}{ Legenda: } & $\begin{array}{l}\text { Hyundai } \\
\text { HB20 }\end{array}$ & 1,00 & 0,01 & 0,00 \\
\hline \multicolumn{3}{|c|}{ Há diferença estatística $(p \leq 0,05)$} & $\begin{array}{c}\text { Renault } \\
\text { Kwid }\end{array}$ & 1,00 & 0,00 \\
\hline \multicolumn{4}{|c|}{ Não há diferença estatística $(p>0,05)$} & VW Fusca & 1,00 \\
\hline
\end{tabular}

Para os mais entusiastas foram encontradas diferenças estatisticamente significativas entre os pares Onix e Ka; Onix e Kwid; Onix e Fusca; Onix e Uno; HB20 e Uno (tabela 4).

Tabela 4: Comparação dos pares por teste de inferência Friedman 2-way ANOVA.

\begin{tabular}{|c|c|c|c|c|c|}
\hline \multicolumn{6}{|c|}{ Resultado - Entusiastas (níveis 4 e 5 ) } \\
\hline & Ford Ka & $\begin{array}{c}\text { Hyundai } \\
\text { HB20 }\end{array}$ & $\begin{array}{c}\begin{array}{c}\text { Renault } \\
\text { Kwid }\end{array} \\
\end{array}$ & VW Fusca & Fiat Uno \\
\hline GM Onix & 0,00 & 0,56 & 0,01 & 0,00 & 0,00 \\
\hline & Ford Ka & 1,00 & 1,00 & 1,00 & 0,32 \\
\hline \multicolumn{2}{|c|}{ Legenda: } & $\begin{array}{l}\text { Hyundai } \\
\text { HB2O }\end{array}$ & 1,00 & 0,95 & 0,00 \\
\hline \multicolumn{3}{|c|}{ Há diferença estatística $(p \leq 0,05)$} & $\begin{array}{l}\text { Renault } \\
\text { Kwid }\end{array}$ & 1,00 & 0,27 \\
\hline \multicolumn{4}{|c|}{ Não há diferença estatística $(p>0,05)$} & VW Fusca & 1,00 \\
\hline
\end{tabular}

Os valores de mediana apontaram similaridade entre as amostras nos três diferentes grupos - Fusca e Uno, sempre com mediana 5, e Ka, sempre com mediana 4, sendo que Kwid e HB20 tiveram uma diferença no grupo dos não entusiastas (níveis 1 e 2) com mediana 3, enquanto nos outros dois grupos obtiveram mediana 4.

Assim, para o grupo dos não entusiastas (1 e 2), Uno e Fusca continuam sendo os mais "populares", seguidos do Ka. Para eles, Onix, Kwid e HB20 são intermediários entre "populares" e "não populares". Já entre os parcialmente entusiastas (3) e entusiastas (4 e 5), a percepção é que os mais "populares" são Uno e Fusca, seguidos de Kwid, Ka e HB20, sendo o Onix intermediário entre "popular" e "não popular".

\section{Discussão dos resultados}

Do ponto de vista estatístico, a partir da análise dos resultados par a par apresentados, o único modelo que pode ser considerado como mais "popular" é o Uno. Porém, para a maioria dos respondentes, quando se observa apenas os valores das medianas, tanto Fusca quanto Uno foram considerados do mesmo modo, ou seja, na categoria mais "populares". Ambos os modelos obtiveram mediana 5, independentemente do nível de entusiasmo existente em relação a automóveis. Ao se observar os dados gerais, em cada um dos grupos estudados (não entusiastas, parcialmente entusiastas e mais entusiastas), os valores de mediana desses dois modelos foram os mesmos.

Apesar dos valores obtidos pelo Uno levarem-no a ser considerado o mais popular dentre os apresentados, de maneira estatisticamente significativa no grupo geral, essa diferença desaparece quando se observa a análise isolada dos grupos. Nessas situações, não se identificam diferenças significativas sobre o Fusca. Por sua vez, o Fusca não se destacou sobre o Ka em nenhum dos três grupos, sobre o Kwid nos grupos dos parcialmente entusiastas e dos mais entusiastas e sobre o HB20 no grupo dos mais entusiastas. A diferença do Fusca nos três grupos só aparece pelas medianas (de valor 5, ao passo que os outros veículos obtiveram valores entre 3 e 4 ).

Considerando que o diferencial semântico aplicado teve como objetivo analisar a percepção do produto por meio da estética, os valores obtidos permitem identificar que as formas mais simples do Uno e do Fusca se destacam em relação aos outros carros fazendo com que sejam vistos como "mais populares". As medianas de valor 5, tanto no grupo geral quanto nos grupos isolados, apontam para a percepção de valores de compra mais baixo para esses dois modelos. Já o Onix (Md 3 nos três grupos e no grupo geral), o Kwid e o HB20 (Md 3 apenas entre os não entusiastas) trazem uma sensação de serem carros de valor mais alto para parte dos respondentes.

Seria esperado que o Kwid - lançado no final de 2017 no mercado nacional, amplamente divulgado nas mídias como o carro mais barato entre as grandes montadoras ${ }^{4}$, custando R\$ $29.900^{5}$ em sua versão mais básica (aproximadamente US\$ 7.500 no período anunciado), e tendo sido o $4^{\circ}$ automóvel mais vendido no ano de 2019 , conforme a FENABRAVE - tivesse um resultado mais próximo dos clássicos "populares” Uno e Fusca. Porém, isso aconteceu só entre o grupo dos mais entusiastas. Esse fato pode ter ocorrido devido a essas pessoas terem por característica o fato de serem mais atentas aos fatores preço e versões dos veículos.

4- Exclui-se aqui o Cherry $Q Q$, que apesar de custar menos à época era comercializado apenas por importação.

5- Disponível em https://motor1.uol.com.br/features/179088/carros-mais-baratosbrasil/ acesso em 10 jan 1020 . 
O uso das versões chamadas "top de linha" no teste permitiu identificar que a estética do Uno e do Fusca, para os respondentes, impactou como sendo de modelos mais baratos, mesmo quando considerados os modelos mais completos. O mesmo aconteceu com o $\mathrm{Ka}$, com a versão "premium" apresentada nos testes, que obteve mediana 4. Frisa-se que o fato de Fusca e Uno, mesmo fora de linha há anos, serem modelos tradicionais e bem conhecidos do público consumidor brasileiro, constitui uma possível forte influência nos resultados observados.

A longevidade no mercado também pode ter influenciado os resultados obtidos pelo Ka, lançado no mercado nacional em 1997 e, portanto, também já bastante conhecido do público em geral. Em termos estatísticos, foi o que mais se aproximou de Uno e Fusca. Além de a mediana ser igual a 4 em todas as análises, as médias não traziam diferenças significativas estatisticamente entre os pares com o Fusca e o Kwid em todos os grupos, além de não ter diferença significativa com o Uno entre os entusiastas. Porém, qualquer afirmação no sentido de que o tempo de vida no mercado pode influenciar diretamente na percepção estética do modelo em relação ao seu preço de compra é inapropriada de ser tirada neste estudo. Ainda assim, identificar o Uno e o Fusca como os automóveis mais populares em todos os grupos corresponde ao esperado quando se considera a história de ambos os veículos e corrobora com o apresentado em [3].

Por fim, o Chevrolet Onix, apontado por todos os grupos analisados como "o menos popular" (Md 3), destacase. Diferentemente de um carro com aparência simples e poucos equipamentos, o consumidor enxerga no Onix um veículo que "não tem cara de ser tão popular" - o que é ideal para quem busca um carro que aparenta ser mais caro. Entende-se, portanto, que apesar do Onix ser o modelo de entrada da fabricante, devido à sua estética ele não é percebido pelos respondentes dessa maneira.

\section{Conclusões}

Os chamados "compactos premium" - mais novos e com desenhos mais atuais, porém mantendo apenas equipamentos essenciais - serão dominantes na tendência da estética para o projeto de veículos "populares", uma vez que tendem a possuir um visual estético que os aproxima das versões mais caras dos mesmos modelos. A GM ainda mantém o Onix da geração anterior, chamado agora de Joy, para atender à demanda de quem busca um carro mais barato. Conclui-se, portanto, que, ao adquirir um veículo com desenho mais atual, o consumidor não se enxerga dentro de um carro "popular".

Os resultados obtidos mostram que a estética do produto pode ser o diferencial para que se crie uma identificação entre o usuário e o automóvel. Tal fato é corroborado pelo fato do GM Onix, carro mais vendido em 2019 e o mais barato da fabricante no Brasil, possuir uma estética rebuscada e não ser visto pelo público respondente, nem mesmo pelos autodeclarados entusiastas, como um automóvel "popular".

O estudo apresenta limitações metodológicas relacionadas à abrangência e à aleatoriedade da amostra. Embora a amostra de 109 respondentes pareça ser escassa em relação à população usuária dos automóveis, considera-se que, como análise de caso, é relevante observar as relações entre o design de produto e estratégias de marketing, inclusive de grandes empresas multinacionais. Assim, possibilita-se que futuros estudos sobre a temática possam ser desenvolvidos, considerando diferentes aspectos (p.e. geográficos ou sociais) que possam influenciar a análise da relação entre a concepção do produto e as estratégias de marketing, contribuindo assim para a compreensão do ato de consumo na sociedade contemporânea.

A análise realizada mostrou que a relação do consumidor com o produto faz com que ele opte, em caso de similaridade nos preços de venda, pelo carro que combina mais com o que deseja aparentar no meio social. Isso faz com que as montadoras e seus designers direcionem os projetos dos carros "de entrada" para produtos com aparência "premium", com desenhos mais atuais, porém mantendo apenas equipamentos essenciais.

O consumidor de automóveis "populares" no Brasil não se interessa mais pela compra de um veículo espartano e esteticamente pobre se não for por extrema necessidade ou por questões unicamente financeiras. Nos lançamentos mais recentes das montadoras já se identifica a tendência de migração do processo de simplificação de modelos já existentes para o desenvolvimento de novos produtos, que abarquem versões mais diversificadas em termos de preço final. Mesmo que seja necessário assumir um custo um pouco maior, o consumidor tende a pender para o modelo mais "bonito" ou mais atual.

Considerando que a compra de um automóvel envolve suprir a necessidade do usuário e trazer a ele prazer, além de lucro para as montadoras, cabe às fabricantes entenderem os anseios do público-alvo para, então, lançarem produtos que atendam requisitos de seu consumidor, inclusive sob o ponto de vista cultural. Sendo o carro "popular" um produto de sucesso, visto a condição econômica média da população, é importante desenvolver o modelo de maneira a se adequar às necessidades de seu usuário.

\section{Agradecimentos}

O presente trabalho é parte das atividades do Projeto DINTER UFMA/UNESP e foi desenvolvido com apoio da Coordenação de Aperfeiçoamento de pessoal de Nível Superior - Brasil (CAPES); da Fundação de Amparo à Pesquisa e ao Desenvolvimento Científico e Tecnológico do Maranhão (FAPEMA - edital 012/2016, processo 04206/2016) e do CNPq (Processo 304619/2018-3). 


\section{Referências bibliográficas}

1. LöвACH, Bernd. Design Industrial: Bases para a configuração dos produtos industriais. 1a. ed. São Paulo: Blucher, 2001. 206 p.

2. DE VASCONCELLOS, Eduardo Alcântara. Mobilidade Urbana: O que você precisa saber. São Paulo: Companhia das Letras, 2013. E-book Kindle.

3. LARICA, Neville Jordan. Design de transportes: Arte em função da mobilidade. 1a. ed. Rio de Janeiro: 2AB / PUC-Rio, 2003. 216 p.

4. CONTESINI, Leonardo. Muito antes do Kwid: os (sensacionais) carros depenados do passado. 2017. Disponível em: $<$ https://www.flatout.com.br/muito-antes-do-kwidos-sensacionais-carros-depenados-do-passado/>. Acesso em: 21 dez. 2019.

5. GIUCCI, Guillermo. A vida cultural do automóvel: percursos da modernidade cinética. Rio de Janeiro: Civilização Brasileira, 2004. 367 p.

6. SIMCOE, Michael. [Entrevista concedida a] Dan Sandberg. Brembo Red, Itália, episódio 2. Disponível em: $<$ https://www.brembo.com/en/company/news/brembored-episode-2\#> Acesso em: 10 dez. 2019.

7. hePtinstall, Simon (ed.). 1001 Carros: Para dirigir antes de morrer. 1. ed. Rio de Janeiro: Sextante, 2013. 960 p.

8. ATIYEH, Clifford. Where's Willys: The 30-Plus Easter Eggs We Found on the Jeep Renegade. 2015. Disponível em: $<$ https://www.caranddriver.com/features /g15380362/ jeep-renegade-easter-eggs/> . Acesso em 21 dez. 2019.

9. косн, Silvia orsi. STEYER, Henrique. Uau!: design, emoção e experiência. 1. ed. Curitiba: Appris, 2016. E-book Kindle.

10. HERNANDES, Dalmo. Afinal, quem inventou o carro popular?. 2019. Disponível em: <https://www.flatout.com. br/afinal-quem-inventou-o-carro-popular/>. Acesso em: 21 dez. 2019.
11. oCDE / Eurostat. Manual de Oslo 2018: Diretrizes para coletar, relatar e usar dados sobre inovação. 4. ed. Luxemburgo: OCDE Publishing, Paris / Eurostat, 2019.

12. SILVA, Danilo Correa; BOTURA JR, Galdenoro; PASCHOARELLI, Luis Carlos. Inovação e pesquisa em design nas universidades brasileiras. Design e Tecnologia, v. 3, n. 06, p. 1-12, 31 dez. 2013.

13. MERCALDI, Marlon; BARCELLOS, Ekaterina; BOTURA JR, Galdenoro. Uma visão conceitual da inovação no design brasileiro. Fourth international conference on design, engineering, management for innovation. p. 45-55, 2015.

14. HERNANDES, Dalmo. Quais são os carros mais vendidos de todos os tempos ao redor do mundo?. 2016. Disponível em: < https://www.flatout.com.br/quais-sao-oscarros-mais-vendidos-de-todos-os-tempos-ao-redordo-mundo/>. Acesso em: 12 jan. 2019.

15. PEREIRA, Fabiano. Fiat Uno Mille: o carro das multidões. 2016. Disponível em: $<$ https://quatrorodas.abril.com. br/noticias/fiat-uno-mille-o-carro-das-multidoes/>. Acesso em: 10 dez. 2019.

16. CESAR, Julio. Carros para sempre: Uno Mille, a história do precursor dos "populares". 2013. Disponível em: <https://motor1.uol.com.br/news/117608/carros -para-sempre-uno-mille-a-historia-do-precursor-dospopulares/>. Acesso em: 12 jan. 2020.

17. GRECo, Enio. Saiba quanto custariam os carros populares da década de 1990 nos valores atuais. 2019. Disponível em: <https://estadodeminas.vrum.com.br/app/noticia/noticias/2019/06/29/interna_noticias,53725/quanto-custariam-os-populares-da-decada-de-1990-em-valores-atuais.shtml>. Acesso em: 21 dez. 2019. 